\title{
LA EJECUCION NORMATIVA DEL DERECHO DE LA COMUNIDAD EUROPEA POR LAS COMUNIDADES AUTONOMAS
}

\author{
por
}

\section{José-Luis Sánchez Díaz}

Secretario de Primera Categoría de Administración Local

Profesor de Derecho Administrativo Económico en la Facultad de Ciencias Económicas y Empresariales de la Universidad de Murcia

SUMARIO: I. INTRODUCCION.-II. LAS COMUNIDADES AUTONOMAS Y LA EJECUCION DE LOS TRATADOS INTERNACIONALES Y ACTOS NORMATIVOS DE SUS ORGANIZACIONES. III. LOS INSTRUMENTOS NORMATIVOS DE FORMULACION POR LAS COMUNIDADES AUTONOMAS DEL DERECHO COMPLEMENTARIO AL ORDENAMIENTO EUROPEO: 1. FACTORES DETERMINANTES EN LA ELECCIÓN DEL INSTRUMENTO NORMATIVO APROPIADO: NATURALEZA DE LA COMPETENCIA AUTONÓMICA Y RELACTÓN ENTRE LEY Y REgLAMENTO. 2. LA COMPLEMENTACIÓN NORMATIVA: A) Reglamentos y Decisiones CECA. B) Directivas CEE y Recomendaciones CECA. C) Decisiones. D) Recomendaciones y Dictámenes.-IV CONCLUSIONES.

\section{INTRODUCCION}

Alcanzada en España una nueva distribución territorial del poder con la instauración del Estado autonómico, sobreviene para nuestro País la incorporación a la Comunidad Europea. El hecho 
presenta una singular trascendencia, por cuanto puede afectar, de nuevo, al esquema funcional y orgánico en que se desenvuelve la acción pública, lo que puede suponer una reducción de las competencias de los poderes internos tanto desde una perspectiva territorial como funcional.

La doctrina extranjera y española no han dejado de ser sensibles a uno y otro problema (1). Así, en orden a la distribución territorial del poder, L. PARejo Alfonso precisa que no cabe decir, en puridad, que la integración en las Comunidades Europeas lesiona, con carácter general, la economía del reparto interno de competencias. Este continúa inalterado en los propios términos con que lo establece la Constitución. "Sucede sólo que la existencia o no de espacio material hábil para el ejercicio de las competencias y, en su caso, la extensión del mismo dependerán, desde luego, de la existencia o no de Derecho europeo y del espacio ocupado por éste, pues sólo en el restante podrán operar realmente las competencias internas con su lógica propia» (2).

Por otra parte, en cuanto afecta a la atribución de funciones y a las relaciones entre Parlamentos y Ejecutivos, Santiago MUÑoz MACHaDo pone de relieve "cómo Países democráticos europeos, que con tanto esfuerzo han construido los dogmas de la reserva de ley, el principio de legalidad, han articulado un sistema de fuentes bien claro y definido y, en fin, han atribuido a las asambleas representativas la adopción de las decisiones políticas fundamentales expresadas mediante leyes, están aceptando, con mayor o menor entusiasmo, según las épocas y los Países, que el protagonismo de los Ejecutivos nacionales haya aumentado en detrimento del peso de las asambleas, que la participación de éstas en la formación de la legislación interna esté cada día más encerrada dentro de los límites que la Comunidad marca, que las normas europeas se impongan siempre e incontestablemente a las leyes internas y aun a algunos contenidos de los propios textos constitucionales, que normas tan irresistibles se elaboren y aprueben por órganos integrados, todo lo más, por representantes de los Ejecutivos nacionales y no por órganos directamente elegidos» (3).

Las garantías de los derechos y libertades reconocidos constitucionalmente se ven incluso afectadas en esta situación. La reserva de ley establecida en el artículo 53 , párrafo $1 .^{\circ}$, de la Constitución 
española para regular el ejercicio de los derechos y libertades incorporados al capítulo II del Título I, tiene ya un alcance limitado al Derecho interno. Basta pensar en la decisiva influencia que la actuación del Consejo y la Comisión tendrán sobre la libertad de empresa, reconocida en el artículo 38 de la Constitución, o el impacto que las directrices impositivas comunitarias pueden presentar respecto al principio de capacidad económica del contribuyente, inspirada en la igualdad y progresividad tributaria (art. $31 \mathrm{CE}$ ).

El proceso tiene ciertamente un carácter evolutivo, que a la larga es probable que se muestre propicio a la incorporación de fórmulas que permitan un mayor control de la Comisión y Consejo europeos y un más acentuado protagonismo en las funciones legislativas, a través del Parlamento europeo. En la medida en que tal institución se configure con poderes más amplios quedará instaurado un equilibrio funcional, que parece deseable. Sin embargo, si no se logra una solución adecuada, puede verse deteriorado el papel de las Asambleas o Parlamentos nacionales, y especialmente de los órganos legislativos territoriales, que podrían ver desdibujada su imagen de poderes autónomos. Las disposiciones de la Comunidad Europea y las propias del Estado en que se insertan pueden ir reduciendo el ámbito autonómico de las Entidades territoriales. Si las Comunidades Autónomas perdiesen total o parcialmente la autonomía que deriva de su potestad legislativa entrarían en una dinámica evolutiva, que las transformaría en Entidades con simple autonomía administrativa o con autonomía política muy limitada.

Y esta evolución tiene, además, una traducción vertical que afectaría al contenido funcional de las Entidades locales. Las Comunidades Autónomas presentan en la actualidad un importante aparato burocrático instaurado sobre la idea de gestión de las competencias que les han sido transferidas y que, en términos generales, recogen las que en su día fueron retiradas a los Municipios y Provincias en un proceso que se adentra en el pasado siglo. La Ley Básica de Régimen local de 2 de abril de 1985 supone un intento importante de articular las relaciones entre Comunidad Autónoma y Administración local, al reconocer a las Provincias y Municipios un ámbito de competencias propias y admitir, al mismo tiempo, la posibilidad de que ejerzan funciones delegadas en materias cuya titularidad corresponde a las Comunidades Autónomas (4).

La Ley del Proceso autonómico abundaba también en la misma 
idea, al permitir a las Comunidades Autónomas delegar funciones de naturaleza ejecutiva en las Diputaciones Provinciales, como ha sido reconocido en la vigente Ley Básica de Régimen local de 2 de abril de 1985.

Todo este esquema de articulación se ha de ver, pues, afectado por la integración de España en la Comunidad Europea y el desplazamiento de poder que, según hemos visto, se produce hacia órganos supranacionales. Si las Comunidades Autónomas perdieran parte de su autonomía política o, al menos, la vieran disminuida, por el consiguiente menoscabo de sus facultades legislativas en un proceso más o menos largo, de reincorporación de competencias normativas al Estado o traslación de las mismas a la Comunidad Europea, podría quedar bloqueado este intento de articulación que se recoge en la Ley Básica de Régimen local, en base a la descentralización o delegación de funciones ejecutivas en favor de las Entidades locales.

Desde esta perspectiva, resulta adecuado hacer una interpretación de las relaciones Estado-Comunidades Autónomas, de tal modo que éstas mantengan sus funciones normativas, que cada Estatuto reconoce como elemento imprescindible para su autonomía política. A la vez, estos Entes territoriales limitarían su organización y la disponibilidad de medios personales y financieros a la satisfacción de los intereses generales de la Región, sin interferir o menoscabar las facultades de gestión propias de Municipios y Provincias. La Administración local podría, además, constituirse en administración gestora, vía delegación, de las competencias asumidas por las Comunidades Autónomas. Sin embargo, si parte de las competencias normativas o directivas de los Entes territoriales quedaran limitadas por pasar a manos de otras organizaciones estatales o supraestatales, las Comunidades Autónomas difícilmente se desprenderían del ejercicio de funciones ejecutivas, único reducto efectivo que les quedaría; y, de este modo, podría quedar bloqueado cualquier intento descentralizador de la función administrativa de los servicios públicos de la Administración local. La propia estructura administrativa de las Administraciones territoriales y locales, que debe ser proporcionada a las atribuciones que realmente ejercen, podría plantear dificultades de articulación entre Comunidades Autónomas y Entidades locales de imprevisible evolución. 


\section{LAS COMUNIDADES AUTONOMAS Y LA EJECUCION DE LOS TRATADOS INTERNACIONALES Y LOS ACTOS NORMATIVOS DE SUS ORGANIZACIONES}

Las consideraciones anteriores nos conducen a pensar la distribución de competencias entre el Estado, las Comunidades Autónomas y los Entes locales, cara a la integración de España en las organizaciones europeas, como un engranaje que debe ser perfectamente articulado para que sea operativo, y esta articulación debe encajar en los Estatutos de Autonomía de cada Ente territorial y en el marco general de la Constitución. Araceli Mangas Martin destaca en este sentido que cuando España presta su consentimiento de obligarse mediante un Tratado lo hace en el estricto respeto a su orden constitucional, del que es piedra angular el sistema autonómico; por ello, la aplicación del Tratado se hará por el Estado o por las Comunidades Autónomas, según estén ordenadas constitucionalmente tales competencias a las que se refiere el Tratado (5).

La distribución de competencias entre los distintos Poderes públicos territoriales requiere, pues, un planteamiento global, que complete esa nueva realidad, y asigne a cada Administración en el conjunto de la Comunidad Europea cometidos normativos y de ejecución, conforme a los criterios ya establecidos en la Constitución y en los propios Estatutos de Autonomía.

La especificación concreta de las atribuciones correspondientes al Estado y a las Comunidades Autónomas fue llevada a efecto, hasta que se concluyó el proceso de transferencias, en virtud de Reales Decretos, a propuesta de las Comisiones Mixtas de Transferencias, que sustanciaban las dificultades interpretativas de los Estatutos de Autonomía en relación con la Constitución y preveían la asignación de medios personales y materiales basados en el sistema normativo en vigor en el momento de la transferencia. Es decir, se partía de las atribuciones que la legislación vigente confería al Estado en cada materia y se hacía un reparto de dichas atribuciones en aplicación de las competencias asumidas en el Estatuto de Autonomía. La existencia de una normativa nueva emanada de las Comunidades Autónomas contempla, pues, actuaciones no previstas en la normativa anterior y plantea, por tanto, la necesidad de asignar estos cometidos bien al Estado, bien a la Comunidad Autónoma, a la luz de 
la Constitución y el Estatuto. Basta pensar en la gestión de la política de ayudas económicas procedentes de los organismos comunitarios (Fondo Social Europeo, Fondo Europeo de Desarrollo Regional...) y también en la ejecución de la política de precios o en la defensa de la competencia.

Todo esto plantea la conveniencia de que un órgano de composición mixta, de igual naturaleza que la Comisión Mixta de Transferencias, coordine un esquema puntual de asignación de atribuciones al Estado y a la Comunidad Autónoma en orden a la aplicación de la normativa comunitaria (6); ello con carácter de urgencia, puesto que ya van apareciendo en el Diario Oficial de las Comunidades, Europeas Directivas, Decisiones y Reglamentos que exigen su complementación normativa o la ejecución por parte de las Administraciones Públicas españolas. Citamos a título de ejemplo los Programas de Operaciones Integradas de Desarrollo, que tienen un carácter prioritario en la Dirección General XVI (Política Regional) de la Comisión de las Comunidades Europeas. En ellos se pretende. coordinar las acciones y movilizar recursos de las Administraciones centrales, regionales, locales, junto con las actuaciones del FEDER, FEOGA y Fondo Social Europeo.

La perspectiva que hemos dejado apuntada puede servirnos de criterio para orientar el Derecho autonómico en el marco de la normativa comunitaria. Si tomamos como punto de referencia la Comunidad Autónoma de la Región de Murcia, las facultades que ésta tiene, en este orden, vienen recogidas en el artículo 12, 2, del Estatuto de Autonomía, que literalmente señala:

«Corresponde también a la Región la ejecución dentro de su territorio de los Tratados internacionales y los actos normativos de las Organizaciones internacionales en lo que afecte a materias de su competencia».

La lectura del precepto indicado tiene dos puntos de esencial interés para su interpretación: el uso del término ejecución y la: referencia in genere o reenvío estatutario a otros preceptos que delimitan la competencia material de la Comunidad Autónoma.

Si por ejecución entendemos la aplicación al caso concreto de la normativa comunitaria, actividad de mera ejecución, el alcance de las competencias normativas es prácticamente nulo: la Comunidad Autónoma no podrá dictar o aprobar complemento normativo 
alguno de las disposiciones comunitarias. Estos complementos normativos alcanzarían a los Reglamentos en la medida indispensable para su aplicación, dado que el Reglamento constituye una norma completa, y a las Directivas que obligan a todo Estado miembro destinatario a lograr un resultado, dejando a las instancias nacionales la competencia en cuanto a la forma y los medios para conseguirlo (arts. 189 del Tratado CEE y 161 del Tratado CEEA).

$\mathrm{Si}$, al contrario, se partiese de una concepción amplia del término «ejecución» que abarcara, además de los actos de mera ejecución, la «ejecución normativa», esta interpretación, que nos parece acertada, llevaría a admitir que la Comunidad Autónoma de Murcia tiene competencias para complementar, por vía legal o reglamentaria, el Derecho comunitario que no sea de directa aplicación (non self executing) y que se contiene con carácter excepcional en los Reglamentos y de modo más general en las Directivas y Decisiones.

La complementación normativa consistiría para los Reglamentos en precisar su contenido, cuando el propio Reglamento así lo exija, y faculte al Estado para que lleve a efecto esta operación en la medida indispensable para su más correcta aplicación (7). En las Directivas la operación consistiría en crear un Derecho interno que determinara la forma y medios para alcanzar los resultados previstos en la norma comunitaria; y en el caso de la Decisión el legislador nacional ajustaría su conducta al contenido específico de cada una de ellas, dado que los artículos 189 y 161 de los Tratados CEE y CEEA nada especifican al respecto. La motivación de tales Decisiones, que el artículo 190 del TCEE exige, puede servir de punto de partida para llevar a efecto esta actuación.

Las posibles interpretaciones que ofrece el artículo 12, 2, del Estatuto de Autonomía murciano no han pasado inadvertidas por la doctrina que hasta el momento se ha ocupado de las relaciones entre el Derecho interno y el Derecho comunitario.

Así, A. Mangas Martín, tras reconocer la imprecisa frontera del Estatuto de Autonomía de la Región de Murcia, en el que no está claro si la Comunidad Autónoma ha asumido la ejecución plena (desarrollo legislativo, reglamentario y administrativo) o la mera ejecución, se inclina, partiendo de una interpretación sistemática del precepto que pone en relación con el párrafo $10^{\circ}$ del mismo artículo, por incluir a la Región de Murcia entre aquellas en las que las competencias de ejecución son mínimas, mera ejecución admi- 
nistrativa (Asturias, Murcia, Navarra, Extremadura, Baleares y Castilla-León), a diferencia del País Vasco, Cataluña, Andalucía, CastillaLa Mancha, Canarias y Madrid, cuyas facultades de ejecución serían plenas o normativas (8).

Este criterio, que no compartimos, parece necesitado de apoyos. más sólidos que la simple interpretación sistemática del precepto.

De una parte, la expresión «ejecución de Tratados o Derecho derivado de las Comunidades Europeas» no se identifica en cualquier caso con la simple aplicación al caso concreto de esta normativa (9). Es más, la ejecución comprendería, como ya se ha dicho, la complementación normativa necesaria en los casos de disposiciones no directamente aplicables. Bajo el término ejecución designa S. MUÑoz MACHADo una serie de operaciones variadas que en la jerga comunitaria suelen delimitarse con la expresión, más amplia y expresiva, de mise en oeuvre, que no son sólo el desarrollo normativo de las disposiciones europeas, sino su trasposición al Derecho interno, la adaptación y armonización de la legislación propia, la aplicación administrativa de las disposiciones europeas (10). Esta es la interpretación que se reconoce al término ejecución para los Estatutos de las Comunidades Autónomas de Cataluña (el art. 27, párrafo 3, del Estatuto de Autonomía), País Vasco (art. 20, párrafo 3, del Estatuto), Andalucía (art. 23, 3, del Estatuto), Castilla-La Mancha (artículo 34 del Estatuto), Canarias (art. 37, 2, del Estatuto) y Madrid (art. 33, 2, del Estatuto), y que aplicamos igualmente a Murcia.

Conviene advertir que los Estatutos de Autonomía de la Región de Murcia (art. 12, párrafo 2) y Aragón (art. 40, párrafo 2) contienen el reconocimiento más amplio de competencias que se confieren a las Comunidades Autónomas, al abarcar facultades de ejecución, de modo explícito, tanto de los Tratados internacionales como de los actos normativos de las Organizaciones internacionales.

Las demás Comunidades Autónomas tienen facultades de ejecución de los actos normativos de la Comunidad Europea por el carácter derivado que tales actos suponen del Derecho básico contenido en los Tratados que la constituye.

Limitar, por otra parte, las facultades de las Comunidades Autónomas a la aplicación concreta de la legislación de la Comunidadi Europea supondría además una erosión permanente de la autonomía regional en la medida en que aquélla fuese regulando cada una de las materias sobre las que los Estatutos de Autonomía suelen otorgar competencias exclusivas o compartidas y que tienen una 
naturaleza económica. No hay que olvidar que el Estado, en el ámbito en que opera la Comunidad Europea, cuenta además con un título competencial que legitimaría sus atribuciones: la función ordenadora de la totalidad de la actividad económica. Competencia horizontal o transversal que porta -conforme indica L. Parejo ALFONSo en el trabajo citado- en sí mismo una gran vis expansiva, una específica capacidad para ser interpretada extensivamente con simultánea comprensión del ámbito propio de los títulos competenciales sectoriales; aunque añade el citado profesor que el riesgo de eventuales consecuencias reaccionales en las Comunidades Autónomas (que también cuentan con título expansivo, como el de la ordenación del territorio, eficazmente esgrimible en oposición al de la política económica), replantea por sí mismo la pertinencia de la reconsideración de las pautas de producción normativa y, en definitiva, de ejercicio de las competencias. «Este, tanto por parte de las Comunidades Autónomas como por la del Poder central, ha de ser leal, es decir, ponderado o resultante de una evaluación del propio papel que tenga en cuenta el que corresponde asimismo a la otra instancia territorial».

La fuerza expansiva de la ordenación general de la economía, a que se refiere el artículo 131 de la Constitución, ha sido reconocida en reciente sentencia del Tribunal Constitucional número 29/1986, de 20 de febrero (BOE 21 marzo 1986), en los recursos de inconstitucionalidad presentados por la Junta de Galicia contra determinados preceptos del Real Decreto-ley 8/1983, de 30 de noviembre, de Reconversión y Reindustrialización, y de la Ley 27/1984, de 26 de julio, de Reconversión y Reindustrialización.

En esta sentencia se admite la competencia estatal para establecer los planes de reconversión industrial, así como los relativos a las ZUR, por cuanto tales planes exceden, por lo general, del ámbito de competencia territorial de cada Comunidad Autónoma, y señala específicamente que «las exigencias del principio de unidad económica legitiman así la existencia de planes nacionales de reconversión y la atribución al Estado de la competencia para la declaración de las zonas de urgente reindustrialización, así como para elaborar los planes relativos a cada una de ellas».

A estas consideraciones la sentencia añade otras de mayor alcance y contenido cuando dice que «la ejecución de los planes de reconversión, tal como se regula en el Real Decreto-ley 8/1983 y en la Ley $27 / 1984$, supone el ejercicio de competencias indudablemen- 
te estatales...", "en la ejecución de aquellos planes que supone por parte de la Administración Pública la aprobación de los programas de las empresas de reconversión, la asignación detallada de fondos públicos y beneficios fiscales y crediticios, la adopción de las correspondientes medidas laborales y el control y seguimiento del proceso, el Estado no puede estar ausente...» "Todas estas razones determinan el carácter concurrente de las competencias de ejecución estatales y autonómicas o, para ser más exactos, que la ejecución de los planes de reconversión industrial es una tarea común o de responsabilidad común del Estado y de las Comunidades Autónomas, por cuanto requiere la necesaria confluencia del ejercicio de potestades estatales y autonómicas para la consecución de unos objetivos comunes».

Del conjunto de competencias de las Comunidades Autónomas que podrían quedar afectadas por la incorporación de España a la Comunidad Europea destacamos: transportes, agricultura, ganadería, pesca en aguas interiores, marisqueo, acuicultura, protección de ecosistemas para la caza y pesca fluvial, fomento del desarrollo económico en la Comunidad Europea, empresas públicas, política juvenil, bienestar y servicios sociales, fomento de la cultura y de la investigación, promoción y ordenamiento del turismo... Las amplias posibilidades de actuación que el artículo 235 del Tratado CEE ofrece a la Comunidad Europea, junto a la inexistencia de un listado de competencias, conforme a la técnica utilizada en la generalidad de los Estados pluricéntricos, que concrete las que pueden ejercer los órganos comunitarios, y la expansiva interpretación que del citado precepto ofrece al Tribunal de Justicia de las Comunidades Europeas hacen posible cuanto se acaba de decir. Las competencias de la Comunidad Europea se ejercen en función de los fines y objetivos que ésta persigue, y el Consejo, por unanimidad, a propuesta de la Comisión y oída la Asamblea, podrá adoptar las disposiciones pertinentes para la consecución de los fines señalados en los artículos $2 .^{\circ}$ y $3 .^{\circ}$, en aquellos casos en que el Tratado no haya previsto las potestades necesarias al respecto (art. 235 TCEE). Por otra parte, la aplicación que el Tribunal de Justicia de las Comunidades Europeas hace de estos artículos, admitiendo como legítima cualquier actuación que tenga por resultado la consecución de los fines y objetivos de la Comunidad, establecidos en los artículos $2 .^{\circ}$ y $3 .^{\circ}$ del Tratado de Roma (técnica del efecto necesario), cons- 
tituye un factor importante para la ampliación de las competencias de los órganos de la Comunidad Europea.

Resumiendo cuanto se ha indicado, es procedente señalar que tanto el sentido o significación del término ejecutar como los posibles efectos sobre las competencias de las Comunidades Autónomas, que se verían notablemente reducidas si se priva a éstas de sus facultades normativas por el efecto-desplazamiento de la norma de la Comunidad Europea, son razones que justifican una interpretación favorable a que las Comunidades Autónomas puedan ejercer competencias de ejecución normativa. También es oportuno destacar que con objeto de conseguir a nivel de Estado este objetivo, convendría que aquellas Comunidades Autónomas cuyos Estatutos no prevén competencias de ejecución normativa (Asturias, Extremadura, Baleares y Castilla-León) asumieran dichas facultades por vía de Ley marco o delegatoria, conforme a los párrafos 1 y 2 del artículo 150 de la Constitución española.

Por otra parte, y como argumento adicional en relación con la Comunidad Autónoma de la Región de Murcia, interesa poner de relieve que una interpretación contextual o sistemática del precepto que acoge las competencias de ejecución tampoco conduce a conclusiones distintas. El artículo 12, párrafo 2, del Estatuto de Autonomía murciano difiere en esta materia de modo clarísimo de la regulación que se contiene en los Estatutos de las Comunidades Autónomas en cuyo grupo Araceli MaNGas encuadra el Estatuto de Autonomía de la Región de Murcia (Asturias, Navarra, Extremadura, Baleares y Castilla-León). Si tomamos como punto de referencia el Estatuto de Asturias se advierte que en el artículo 12, apartado b), el Principado asume efectivamente la competencia de ejecución de los Tratados internacionales, en los términos que establezcan las leyes y normas reglamentarias que en desarrollo de su legislación dicte el Estado. En iguales o muy semejantes términos se expresan el artículo 9. del Estatuto de Autonomía de Extremadura, el artículo 12, 1, del Estatuto de Baleares y el 28, párrafo 7, del Estatuto de Castilla-León; sin embargo, el Estatuto de Autonomía de la Región de Murcia se aparta literal y sistemáticamente de la redacción ofrecida por los demás Estatutos indicados. El párrafo 1. del artículo 12 del EAM recoge un conjunto de materias sobre las que la Comunidad Autónoma ejerce facultades de ejecución en "los términos que establezcan las leyes y normas complementarias", mientras que el párrafo $2 .^{\circ}$ del mismo artículo se aparta muy claramente de la 
redacción dada al párrafo $11^{\circ}$ y elimina la sumisión a la normativa estatal, como ocurre en el Estatuto asturiano y en los demás anteriormente enumerados.

Las Comunidades Autónomas, por consiguiente, y en lo sucesivo, deberían llevar a efecto una adecuación de su propia normativa en vigor a las disposiciones comunitarias que afecten a su propia competencia y, asimismo, deberían igualmente proceder a complementar por vía normativa que resulte procedente los Reglamentos, Directivas y Decisiones que afecten a su ámbito interno de competencias. En este mismo sentido, la Ley de 25 de diciembre de 1985 ha previsto ya para el Estado tales actuaciones y ha delegado en el Gobierno mediante la citada Ley, que tiene el carácter de Bases, la adecuación al Ordenamiento jurídico comunitario de determinadas leyes incluidas en un anexo del texto legal y el desarrollo de normas comunitarias, en su totalidad Directivas, en la medida que tal desarrollo exija de una ley y no se hallen actualmente reguladas. En términos muy semejantes, la Comunidad Autónoma del País Vasco ha autorizado la misma técnica delegatoria a favor del Gobierno, con la misma finalidad, por Ley 2/1986, de 19 de febrero, de Bases sobre la Recepción del Ordenamiento de las Comunidades Europeas en el ámbito de la Comunidad Autónoma del País Vasco (Boletín Oficial del País Vasco de 14 de marzo de 1986, núm. 51).

La falta de adaptación del Derecho interno al de las Comunidades europeas no debe suponer, empero, obstáculo alguno para la aplicación del Derecho comunitario. Si el Derecho español fuese contrario al emanado de las Comunidades europeas, aquél resultaría inaplicable, conforme al principio de primacía (11). En igual sentido hay que admitir que en tanto la Comunidad Europea no ejerza potestades normativas en una determinada materia regirá el Derecho interno, estatal o territorial, sin que, por tanto, y a priori, puedan admitirse ámbitos de competencias reservadas a la Comunidad Europea. Excepcionalmente, sin embargo, el Tribunal de Justicia ha reconocido este carácter a algunos sectores o ámbitos de actuación, como la política comercial común (12) y la adopción de medidas de conservación de los recursos biológicos del mar en el marco de la política económica común de pesca (13).

Particular importancia presenta el régimen de ayudas económicas a las empresas a que se refiere el artículo 93 del Tratado CEE, cuyo párrafo $3 .^{\circ}$ exige que la Comisión ha de ser informada de los proyectos dirigidos a establecer o modificar ayudas con la suficien- 
te antelación para que ésta pueda presentar observaciones, señalando que el Estado miembro interesado no podrá ejecutar las medidas proyectadas antes de que en dicho procedimiento haya recaído decisión definitiva (14).

\section{LOS INSTRUMENTOS NORMATIVOS DE FORMULACION POR LAS COMUNIDADES AUTONOMAS DEL DERECHO COMPLEMENTARIO AL ORDENAMIENTO EUROPEO}

La determinación del instrumento normativo adecuado para completar el Ordenamiento jurídico de la Comunidad Europea, a nivel de Comunidades Autónomas, estará en función del carácter o naturaleza de la competencia y del modo en que cada Estatuto de Autonomía regule las relaciones entre Ley y Reglamento.

\section{FACTORES DETERMINANTES EN LA ELECCIÓN DEL INSTRUMENTO NORMATIVO APROPIADO: NATURALEZA DE LA COMPETENCIA AUTONOMICA Y RELACIÓN ENTRE LEY Y REGLAMENTO}

En primer término resulta adecuado señalar que los instrumentos normativos cuando una Comunidad Autónoma detenta competencias exclusivas son más amplios que cuando lo hace con carácter compartido. Las competencias exclusivas suponen el ejercicio de la potestad normativa plena: legislativa y reglamentaria, mientras que cuando la Comunidad Autónoma opera en el ámbito de competencias compartidas, las facultades normativas se limitan al desarrollo legislativo y la potestad reglamentaria.

Las competencias exclusivas se ejercen en relación con materias en las que la Comunidad Europea proyecta gran parte de su actuación, tales como agricultura y ganadería, transportes, pesca en aguas interiores, marisqueo, acuicultura, protección de ecosistemas para la caza y la pesca fluvial, fomento del desarrollo económico (incluida, por tanto, política de subvenciones), empresas públicas, política juvenil, bienestar y servicios sociales, fomento de la cultura y de la investigación y promoción del turismo.

Por otra parte, suelen incluirse entre las competencias compartidas la acción pública en materia de montes y aprovechamientos forestales, ordenación y planificación de la actividad económica regional, régimen minero y energético, sanidad e higiene; materias to- 
das éstas sobre las cuales, de igual modo, la Comunidad Europea suele pronunciarse a nivel legislativo.

Finalmente, las Comunidades Autónomas deberán ejercer su función meramente ejecutiva en otras materias en las que existirá una normativa estatal y comunitaria, que habrá de ser aplicada mediante actuaciones concretas y determinadas.

Conviene precisar también que aunque los Estatutos de Autonomía constituyen título suficiente y adecuado para la disponibilidad de la competencia, los Decretos de transferencias, empero, en cada una de las materias, han limitado en algunos casos las facultades que tan genéricamente se establecían, y esto ocurre de modo singular en materia de ayudas para el fomento del desarrollo económico, en cuya actuación, a veces, las Comunidades Autónomas han venido actuando más como Entes gestores que decisores en el otorgamiento. $\mathrm{Y}$ esto tiene especial significación, incorporados ya a la Comunidad Europea, por cuanto es importante el papel gestor que a la Administración Pública española le corresponderá, en ejecución de la política de subvenciones que a través de sus organismos institucionales, FEOGA y Fondo Social Europeo, fundamentalmente, viene practicando la Comunidad Europea.

\section{LA COMPLEMENTACION NORMATIVA}

En segundo lugar, la selección del instrumento normativo apropiado para complementar el Derecho europeo es un problema de orden interno, propio del Ordenamiento jurídico de cada Comunidad Autónoma, que se resuelve si se tiene en cuenta el planteamiento que a nivel estatutario se haga de las relaciones entre Ley y Reglamento. Este es un tema que a nivel constitucional ha sido muy debatido por la doctrina española y sobre el que existen profundas discrepancias entre quienes niegan la existencia de Reglamentos independientes después de la Constitución y quienes afirman su admisibilidad, partiendo del artículo 97 de la Norma suprema española. Desde un punto de vista autonómico, y repasando muy brevemente los Estatutos de Autonomía, podemos decir que los Estatutos de las Comunidades Autónomas de la Región de Murcia y de Madrid admiten de una manera general y muy clara la existencia de Reglamentos independientes y simultáneamente una reserva material de ley a favor de las Asambleas en aquellos casos en que asî se establezca. 
Así, el artículo 32, párrafo 1, del Estatuto de Autonomía de la Región de Murcia atribuye al Consejo de Gobierno «el ejercicio de la potestad reglamentaria en materias no reservadas por el Estatuto a la competencia normativa de la Asamblea regional»; y el artículo 21, párrafo 1, del Estatuto de Autonomía de Madrid atribuye al Consejo de Gobierno «el ejercicio de la potestad reglamentaria en materias no reservadas en el Estatuto a la Asamblea».

Los demás Estatutos de Autonomía se limitan sin más precisiones a reconocer la potestad reglamentaria de los Gobiernos regionales, aun cuando se reconocen determinadas y concretas reservas materiales de ley a favor de las Asambleas, de modo absoluto o relativo, en el articulado.

Quiere decir todo ello que, con carácter general, nuestros Estatutos de Autonomía más o menos abiertamente aceptan la figura del Reglamento independiente, en cuanto admiten una amplia facultad reglamentaria a los Ejecutivos regionales, tan sólo limitada por las reservas materiales de ley que se establecen en los propios Estatutos. El Reglamento, en definitiva, se ha convertido en nuestras Autonomías en el modo de operar más utilizado, a nivel normativo; las reservas absolutas de ley («sólo por Ley puede ser regulada una determinada materia») quedan limitadas en los Estatutos a muy contados casos, y las demás reservas tienen un carácter relativo que permiten la habilitación al Ejecutivo para ejercer la potestad reglamentaria.

Hechas, pues, estas consideraciones previas, pasamos a exponer la complementación normativa, en cada caso particular: Reglamentos CEE o Decisiones generales CECA, y Directivas CEE o Recomendaciones CECA, haciendo al final de la exposición una referencia a las Decisiones dirigidas a los Estados, que aunque carecen de valor normativo, producen determinados efectos jurídicos, y entre ellos, la vinculación u obligatoriedad del Estado para adoptar las medidas necesarias en su cumplimiento; medidas que en el orden interno pueden traducirse excepcionalmente en disposiciones de carácter general, cuando la Decisión así lo exija.

\section{A) Reglamentos y Decisiones generales CECA}

El Reglamento participa de los requisitos materiales que se atribuyen a las leyes, generalidad e imperatividad directa sobre sus destinatarios. El Reglamento, dice el párrafo $22^{\circ}$ del artículo 189 TCEE, 
será de aplicación general, obligatorio en todas sus disponibilidades y directamente aplicable en cada Estado miembro. Se trata, por tanto, de una norma completa, que no necesita de complemento normativo alguno para su inmediata aplicación.

Estas características no excluyen, sin embargo, la posibilidad de que los Estados miembros dicten normas complementarias de los Reglamentos comunitarios, con carácter excepcional, en la medida indispensable para cumplimentarlos; pero esta actuación posterior en modo alguno excluye la directa aplicabilidad del Reglamento comunitario. El Tribunal de Justicia de las Comunidades Europeas se ha mostrado en este punto cauteloso y ha condenado la reproducción en la normativa nacional de lo establecido en los Reglamentos de la Comunidad Europea y señalado también que son contrarias al Tratado todas las modalidades de aplicación que pudieran tener por consecuencia obstaculizar el efecto directo de los Reglamentos comunitarios y comprometer así su aplicación simultánea y uniforme en el conjunto de la Comunidad (15).

En nuestro Ordenamiento interno la Ley carece de fronteras materiales en relación con su contenido. No existe una reserva reglamentaria, como en la Constitución francesa en vigor; por consiguiente, la Ley podría, en teoría, constituir, junto con el Reglamento interno, instrumento normativo que pudiera complementar en casos excepcionales los Reglamentos comunitarios. Sin embargo, tal posibilidad resulta inadecuada por diversas razones. La primera de ellas deriva del contenido material del propio Reglamento comunitario. Se trata de una norma que excepcionalmente podría exigir complementos de detalle o de desarrollo muy precisos en su aplicación por el Estado. Y esta función la puede cumplir de mejor modo el Poder ejecutivo, más avezado en resolver, por vía particular, precisiones de índole técnica o económica; incluso cabe admitir que el Reglamento, en estos casos de naturaleza ejecutiva, pueda emanar, siempre que así lo reconozca la Ley, de órganos de la Administración inferiores jerárquicamente al Gobierno o su equivalente en las Comunidades Autónomas. Por otra parte, parece poco adecuado al rango y naturaleza de las atribuciones asumidas por las Asambleas legislativas que éstas ejercieran funciones ejecutivas respecto a normas que provengan de la Comunidad Europea.

En relación con las Comunidades Autónomas, también resulta patente que esta potestad reglamentaria adicional se ejercería tanto en el ámbito de las competencias exclusivas como en el de las 
competencias compartidas, puesto que el propio contenido del Reglamento comunitario, por su complitud, es de suponer que contenga no sólo los principios básicos, sino además los aspectos adicionales en que se hubiese desglosado la potestad legislativa interna, sin que sea necesaria una actuación normativa medial del Estado, interpuesta entre la Comunidad Europea y la Comunidad Autónoma. Por otra parte, si la materia respectiva estuviese afectada de reserva legal, esta afectación quedaría limitada a aspectos sustanciales o esenciales que estarían ya regulados por el propio $\mathrm{Re}$ glamento CEE. En este supuesto el espacio normativo a cubrir por la Comunidad Autónoma estaría ya materialmente ocupado por la normativa comunitaria, dado que el Reglamento interno no pasaría de regular cuestiones de detalle.

\section{B) Directivas CEE y Recomendaciones CECA}

Mayor complejidad ofrece la ejecución normativa de las Directivas CEE y Recomendaciones CECA.

La Directiva con carácter general carece de la aplicabilidad de ésta que caracteriza a los Reglamentos comunitarios; debe ser notificada a sus destinatarios y surte efecto a partir de tal notificación (artículo 191 TCEE).

Las Directivas, cuando afectan a una Entidad pública que ha de cumplimentarlas, se dirigen a los Estados miembros; por ello el mero conocimiento que las respectivas Comunidades Autónomas tengan de las Directivas a través del Diario Oficial de las Comunidades Europeas (Serie L, apartado 2) no obliga a éstas ni las vincula directamente, porque no son destinatarias de sus prescripciones ni se ven conminadas por la Comunidad Europea a su cumplimiento. Como ha señalado MARTínez LAGE (16), la inserción en el Diario indicado constituye propiamente un acto de publicidad y no de publicación.

Por otra parte, la Directiva tiene el carácter de una norma materialmente incompleta que adquiere su plenitud y vigencia erga omnes cuando se determinan en una norma posterior, de carácter interno, los medios necesarios para alcanzar los resultados en ella establecidos. Vincula al Estado miembro en la consecución de un objetivo, pero deja a las instancias nacionales la competencia, en cuanto a forma y medios, para alcanzar ese resultado querido por la norma. 
La Directiva no constituye una norma de principios (17), sino una norma de resultados que han de ser conseguidos (art. 189, párrafo 3, Tratado de Roma CEE); por consiguiente, la Directiva no suple necesariamente la legislación básica o de principios que pueda emanar del Estado en el ámbito de competencias compartidas con las Comunidades Autónomas. La consecución de los objetivos o resultados pretendidos por la Directiva puede ser lograda por distintos procedimientos o formas de actuación administrativa: medidas limitativas de los derechos individuales, ayudas al sector privado o asunción por las Entidades públicas de una actividad de prestación. Con cualquiera de estos medios, e incluso con varios de ellos, pueden ser alcanzados los objetivos previstos. Y esta elección de medios está condicionada por principios políticos que trascienden y están por encima de los resultados a alcanzar y que, desde luego, tienen un carácter variable en razón a connotaciones sociales, económicas y políticas en cada Estado.

Las Directivas no constituyen, pues, necesaria e íntegramente una delimitación de principios conforme a los cuales las Comunidades Autónomas hayan de llevar a efecto el desarrollo legislativo, porque la consecución de cualquier resultado puede lograrse por vías o caminos distintos, cuya elección responde a una determinada filosofía política.

Otra consideración a tener en cuenta deriva de la relación entre Ley y Reglamento. La utilización del instrumento normativo apropiado para complementar las Directivas vendrá también en función de las posibles reservas materiales de Ley que existan estatutaria o constitucionalmente. En este punto ya hemos indicado anteriormente la independencia del Reglamento frente a la Ley en los Ordenamientos jurídicos de las Comunidades Autónomas. Por consiguiente, si en la materia en cuestión no existe una reserva legal, el Reglamento o la Ley podrán servir de instrumento normativo adecuado para dar cumplimiento a la ejecución que exija la Directiva comunitaria.

Con estas salvedades previas la utilización de la Ley o del Reglamento para completar la Directiva estará, finalmente, en razón del carácter con el que la Comunidad Autónoma tenga atribuida la competencia normativa:

a) Si se trata de competencias exclusivas de las Comunidades Autónomas, la Directiva podrá ser complementada normativamente por vía legal o reglamentaria, salvo casos de reserva legal. La utiliza- 
ción de la vía reglamentaria, no impediría, sin embargo, que poste. riormente las Asambleas legislativas territoriales aprobasen leyes reguladoras de la materia, que prevalecerian jerárquicamente sobre los Reglamentos autonómicos ya aprobados.

b) Si se trata de competencias compartidas entre el Estado y. la Comunidad Autónoma, a nivel legislativo, y en las que al Estado corresponde la legislación básica y a los Entes territoriales el desarrollo legislativo, nos encontraríamos ante una compleja situación en la que la Comunidad Europea asume la determinación de los resultados a obtener por el conjunto normativo; el Estado, la fijación de los principios o bases legislativas, y las Comunidades Autónomas, la precisión de los intereses territoriales por vía de desarrollo legislativo.

La Comunidad Autónoma, por tanto, ha de respetar en el ejercicio de sus facultades de ejecución normativa no sólo los aspectos que derivan de la nueva distribución territorial del poder, sino además los que resultan de la asignación de funciones al Legislativo territorial. En consecuencia, debemos aplicar el principio de competencia de modo que el desarrollo legislativo no entrase en la formulación de objetivos y respetase a su vez las bases estatales; y el principio de respeto a la distribución funcional del poder, de tal forma que el desarrollo legislativo sólo se llevara a cabo por ley cuando existiere una reserva material en favor de ésta. El Reglamento operaría con carácter independiente y como instrumento válido para la ejecución, a nivel de desarrollo, de la normativa estatal y comunitaria, cuando no existiere reserva material de ley, o cuando existiendo ésta tuviera un carácter relativo y permitiera la habilitación al Ejecutivo para reglamentar.

En cualquier caso, tanto en el supuesto a) (competencias exclusivas) como en el supuesto b) (competencias compartidas) habría que respetar los plazos de ejecución normativa marcados por la $\mathrm{Di}$ rectiva, y esto exige un entendimiento previo entre el Estado y las Comunidades Autónomas o una norma que ordene las relaciones entre ambas Entidades públicas y que establezca plazos perentorios para que cada una de ellas lleve a efecto la ejecución que corresponda.

\section{C) Decisiones}

La Decisión CEEA, que se corresponde con la Decisión individual CECA, tiene carácter vinculante, como el Reglamento y la Di- 
rectiva, y no precisa de ulteriores actuaciones normativas de los Estados, por ser actos singulares de la Comisión o del Consejo que han de ser motivados (art. 190 TCEE). Esto parece que sería razón para eliminar a la Decisión del sistema normativo de las Comunidades Europeas; sin embargo, si tenemos en cuenta que existen Decisiones cuyos destinatarios son la totalidad de los Estados miembros, y que el Tribunal de Justicia ha reconocido la posibilidad de que tengan efecto directo, las Decisiones pueden ser vehículo de expresión de la voluntad normativa comunitaria y, en consecuencia, fuentes del Derecho comunitario en sentido formal (18).

Las Decisiones, por otra parte, constituyen, al igual que los Reglamentos, actos completos que no exigen como regla general posteriores pronunciamientos legislativos. Sin embargo, nada excluye que, en su ejecución, el legislador nacional pueda dictar las medidas necesarias con alcance y contenido normativo, y en estos casos pensamos que la vía procedente sería el Reglamento, que complementase en la medida indispensable el contenido de las Decisiones. Por lo demás, las Decisiones, al igual que las Directivas, tienen por destinatarios a los propios Estados, que son los garantes de su cumplimiento, conforme indica el artículo 93 de la Constitución española, y esto exige, dada la imprecisión que puede plantearse en la adopción de medidas para ejecutarlas, medidas de coordinación entre Estado y Comunidades Autónomas.

\section{D) Recomendaciones y Dictámenes}

Dado que las Recomendaciones y Dictámenes del Consejo y la Comisión no son vinculantes para los Estados miembros de la Comunidad Europea (arts. 189, párrafo final, del TCEE y 161 del Tratado CEEA) carecen del valor de auténticas normas jurídicas.

Sin embargo, como ha destacado Jean-Victor Louis, la Recomendación constituye un instrumento de acción indirecta para armonizar las legislaciones (19). Por otra parte, el Dictamen es otro de los instrumentos que el artículo 118 , párrafo $2 .^{\circ}$, del TCEE prevé para promover la colaboración entre los Estados miembros en el ámbito social. La Recomendación, pues, al invitar a los Estados miembros a encauzar su actuación en un determinado sentido, promueve el pronunciamiento del legislador interno por vía normativa, incorporando, al igual que el Dictamen, un juicio o valoración que indirectamente puede influir en la decisión que se tome. 


\section{CONCLUSIONES}

En resumen, y a modo de conclusiones, señalamos las siguientes:

Primera.-La incorporación de España a la Comunidad Europea no supone a priori alteración alguna en el reparto interno de competencias entre el Estado y la Comunidad Autónoma de la Región de Murcia. Sin embargo, la posibilidad de actuación de la Comunidad Europea en materias de naturaleza económica puede reducir el espacio competencial que la Constitución, el Estatuto o las Leyes atribuyan al Estado o a las Autonomías.

Segunda.-Esta posible minoración de competencias podría afectar sobre todo a la potestad legislativa de las Asambleas regionales. De resultas podría quedar desdibujada la autonomía política de la Comunidad Autónoma por la reducción de su ámbito normativo. La incorporación de España al Mercado Común puede suponer, en cambio, una potenciación e incremento de funciones ejecutivas hasta el momento no asumidas por la Comunidad Autónoma, que vendrían a incrementar las atribuciones del Ejecutivo regional.

Tercera.-En este proceso las Entidades locales están llamadas, conforme a la Ley Básica de Régimen local, a cooperar con las Comunidades Autónomas en la ejecución de la normativa comunitaria en los términos que las leyes determinen.

Cuarta.-Es preciso establecer canales de coordinación (creación de una Comisión mixta, intercambio de información o Conferencias sectoriales entre Ministros y Consejeros del ramo) que permitan concretar las funciones que el Estado o las Comunidades Autónomas van a asumir, de modo que se eviten vacíos normativos o ejecutivos.

Quinta.-La ejecución del Tratado y del Derecho derivado de la Comunidad Europea no se identifican necesariamente con la simple aplicación de la normativa comunitaria. Comprende, además, otras actuaciones que alcanzan la complementación normativa del Derecho de la Comunidad Europea.

Sexta.-Cuando las facultades señaladas en la conclusión anterior no se encuentren reconocidas de modo explícito en los Estatutos de Autonomía resulta adecuado destacar, ante el posible y progresivo desplazamiento de las funciones normativas de las Comunidades Autónomas por el Derecho de la Comunidad Europea, que el artículo 150 de la Constitución permite, por vía de Ley marco 
o delegatoria, atribuir o delegar facultades correspondientes a materia de titularidad estatal.

Séptima.-Los Estatutos de Autonomía de la Región de Murcia (artículo 12, párrafo 2) y Aragón (art. 40, párrafo 2) contienen el reconocimiento más amplio de competencias que se confieren a las Comunidades Autónomas, al abarcar facultades de ejecución, de modo explícito, tanto de los Tratados internacionales como de los actos normativos de las Organizaciones internacionales.

Las demás Comunidades Autónomas tienen facultades de ejecución de los actos normativos de la Comunidad Europea por el carácter derivado que tales actos suponen del Derecho básico contenido en los Tratados que la constituyen.

Octava.-La complementación normativa consistirá para los Reglamentos comunitarios en precisar su contenido, cuando el propio Reglamento así lo exija y faculta al Estado para llevar a efecto esta actuación en la medida indispensable para su correcta aplicación.

En las Directivas la operación consistirá en crear el Derecho interno necesario que determinará la forma y medios para alcanzar los resultados previstos en la norma comunitaria.

En el caso de la Decisión el legislador nacional ajustará su conducta al contenido específico de cada una en particular, dado que los artículos 189 y 161 de los Tratados CEE y CEEA nada especifican al respecto.

Novena.-La determinación del instrumento normativo adecuado para completar el Ordenamiento jurídico de la Comunidad Europea, a nivel de Comunidades Autónomas, estará en función del carácter o naturaleza con que haya sido asumida la competencia y del modo en que cada Estatuto de Autonomía regule las relaciones entre Ley y Reglamento.

En el caso de los Reglamentos comunitarios la norma apropiada para llevar a efecto esta actuación sería el Reglamento ejecutivo, dado que no excedería en su contenido de simples cuestiones de detalle que, como tales, no se consideran materialmente reservadas a la Ley.

En las Directivas, salvo que exista expresa reserva material de Ley, el Reglamento o la Ley, indistintamente, podrán ser instrumentos adecuados para dar cumplimiento a la ejecución normativa que exija la Directiva comunitaria.

Para las Decisiones, por tratarse de actos normativos completos 
que no exigen otros complementarios, bastaría en su caso el Reglamento ejecutivo.

Décima.-Las Directivas no constituyen, en puridad, una delimitación de principios, sino una fijación de resultados, conforme a los cuales las Comunidades Autónomas han de ejecutar su complementación.

Por consiguiente, cuando afecten a materias en las que corresponda a la Comunidad Autónoma tan sólo el desarrollo legislativo, la legislación básica sigue siendo competencia del Estado y no resulta sustituida por el contenido de la Directiva.

Los principios materiales de actuación que la legislación básica ha de contener determinarán, pues, no los resultados, sino los medios que la Comunidad Autónoma ha de poner en ejecución para complementar la Directiva.

\section{NOT A S}

(1) Sobre los aspectos generales del tema se han ocupado, entre otros, los siguientes autores:

Bassanini, Franco; Caretti, Paolo: «Autonomías regionales y poderes comunitarios», Documentación Administrativa, 1981, núm. 191, págs. 241-260.

BIEHL, D.: «El efecto de la ampliación de la Comunidad Europea sobre el desarrollo regional y la política regional», Revista de Estudios Regionales, núm. 5, enerojunio 1980 , págs. $169-204$.

Bognetri, Gionanni: «Le Regioni in Europa: alcune riflessioni sui loro problemi e sui loro destino», Le Regioni, 1984, núm. 6, págs. 1087-1136.

Constantinesco, V.: Compétences et pouvoirs dans les communautés européennes, París, 1974, 492 págs.; págs. 288 y sigs.

Iglesias Buigues, José-Luis: «Federalismo y soberanía en la construcción de la Europa comunitaria», Revista de Instituciones Europeas, 1976, núm. 3, págs. 357 y siguientes.

Institut d'Etudes JuRidiQues EuropénnNEs. Colloque. VII. 1974. Liège: «L'Europe et ses regiones. Actes du...», La Haya: Martinus Nijhoff, 1975.

Lours, Jean-Victor: "Quelques reflexions sur le repartition des competences entre la Communaute Européenne et ses Etats membres», Rev. d'Integration Européenne, 1979, vol. II, núm. 3, págs. 355-374.

MuÑoz MACHADO, Santiago: "La ordenación de las relaciones del Estado y las Comunidades Autónomas con la Comunidad Europea», Revista Española de Derecho Constitucional, 1985, vol. 5, núm. 14, págs. 9-76.

D'ATENA, Antonio: La Regioni Italiane e la Comunità Economica Europea. Università di Catania. Pubblicazioni della Facoltà di Giurisprudenza. Milano. Dott. A. Giuffrè Editore, 1981, 131 págs.

BETRACHTUNGEN ZUM VERHÄLTNIS GEMEINSCHAFTSRECHT-NATIONALES RECHT: «Vortrag: gehalten vor der Juristischen Studien gesellchaft in Karlsruhe» am 26. Juni 1969. Karlsruhe, 1969. («Las relaciones entre el Derecho de la CEE y el Derecho nacional».)

BIRKR, H. E.: Die europäischen Bundesländer in den Europäischen Gemeinschaften. Berlín, 1973.

(Las Regiones europeas en las Comunidades europeas.) 
BunTEN, Vilfried: Staatsgewalt und Gemeinschaftshoheit bei der innerstaatslichen Duchführung des Rechts der Europäischen Gemeinschaften durch die Mitgliedstaaten. Berlín, 1977.

(Poder de estado y soberanía común en la ejecución interior de derecho de la CEE por los Estados miembros.)

Chitti Battel., A.: «Integration Européenne et pouvoirs des Régions». Regionalismus in Europa. Munich, 1983, vol. IV.

(«Integración europea y poderes de las Regiones».)

En España se han ocupado particularmente del tema, además de los autores que citamos en otras notas de este mismo trabajo, los siguientes:

Escribano Collado, P.: «Las Comunidades Autónomas y las relaciones internacionales», en la obra colectiva Comunidades Autónomas, Sevilla, Instituto García Oviedo, 1980.

L'Espagne et les Communautés Européennes: Problèmes poses par l'adhesion: Colloque. 1979. Louvain-la-Neuve: «Colloque organisé par le Centre d'Etudes Européennes et la Faculté de Droit de l'Univ. Catholique de Louvain et par l'Institut d'Etudes Européennes de l'Univ. de Bruxelles». Bruxelles, Univ. de Bruxelles, 1979, $\mathrm{XI}, 420$ págs.

González Casanova, J. A.; Casanovas de la Rosa, O.: "Phénomene régional et integration». Espagne et les Communautés Européennes: Problèmes poses par l'adhesion. Colloque... Bruxelles: Editions de l'Université de Bruxelles, 1979.

Granell, Francisco: "Las Comunidades Autónomas y las negociaciones para el ingreso de España en la Comunidad Europea», Revista de Instituciones Europeas, $1982 / 3$.

- «Las responsabilidades de las Comunidades Autónomas ante la adhesión de España a las Comunidades Europeas», Revista de Instituciones Europeas, Madrid, 1985, núm. 1, págs. 9-27.

LORENTE HURTADo, Fernando: Incidencia del ingreso de España en las Comunidades Europeas en las competencias de las Comunidades Autonomas. Organización territorial del Estado, Madrid, IEF, 1984, vol. II.

Molina DEL Pozo, Carlos-Francisco: Dos estudios sobre Derecho administrativo comunitario: Derecho interno y Derecho comunitario. Las autonomías regionales en España y la adhesión a las Comunidades Europeas, Alcalá de Henares, Instituto Nacional de Administración Pública, 1982, 133 págs.

- «La integración de España en las Comunidades Europeas y su incidencia en el ámbito del Derecho administrativo». Mesa Redonda Hispano-Alemana sobre el tema «Expectativas y preocupaciones hispano-alemanas ante la adhesión de España a las Comunidades Europeas», Madrid, 1980.

NATALI, L.: "Consideraciones acerca del proceso de ampliación de la Comunidad hacia los países ibéricos», Revista de Estudios Regionales, núm. extraordinario, volumen IV, 1982, págs. 15-26.

Parejo Alfonso, Luciano: «Las competencias constitucionales económicas en Alemania Federal», en GARCfA DE ENTERRÍA, E. (dir.): La distribución de las competencias económicas entre el Poder central y las autonomías territoriales..., Madrid, IEE, 1980.

Pérez González, A.; Pueyo Losa, J.: «Comunidades Autónomas y política regional europea». IX Reunión de Estudios Regionales: crisis, autonomías y desarrollo regional, Universidad de Santiago de Compostela, 1985.

ToRnos MAS, J.: "La intervención de las Comunidades Autónomas en la Economía», Revista Española de Derecho Administrativo, núm. 21.

SÁENZ DE VICUÑa Y BARRoso, José: El cumplimiento del Derecho comunitario europeo por parte de las Comunidades Autonomas. Organización territorial del Estado, Madrid, IEF, 1984, vol. IV.

VARIOS AUTOREs: Constitución, Comunidades Autonomas y Derecho Internacional, Santiago de Compostela, 1982.

WRIGHT, Vincent: «Regioni e regionalizzazione in Francia, Italia e Spagna», Le Regioni, 1984, núm. 6, págs. 1116-1180.

Ruilova SANTANA: «Repercusiones del ingreso de España en la Comunidad Europea 
sobre la constitución del Estado de las Autonomías. Aspectos generales», en la obra colectiva La integración de España en las Comunidades Europeas y las competencias de las Comunidades Autonomas.

(2) Parejo Alfonso, L.: «El ordenamiento español y la integración en las Comunidades Europeas: un problema capital de renovacion», Revista Actualidad Administrativa, núm. 1, 1986, pág. 4.

(3) Muñoz Machado, S.: El Estado, el Derecho interno y la Comunidad Europea, Civitas, Madrid, 1986, pág. 30.

(4) Sosa Wagner, F., y De Miguel Garcia, P., en Las competencias de las Corporaciones locales, Instituto de Estudios de Administración Local, Madrid, 1985. Tras hacer un ponderado análisis de las competencias propias, transferidas o delegadas y asignadas o encomendadas a las Corporaciones locales, destacan a modo de reflexion final la proliferación de órganos políticos periféricos de las Comunidades Autónomas, que hoy por desgracia pueden constatarse, como un paso atrás en la configuración del Estado autonómico. Asimismo ponen de relieve la necesidad de prever fórmulas de coordinacion para el ejercicio de las competencias que permitan sortear las trabas que un desaconsejable aislamiento produciría en la consecución de los objetivos políticos que los sujetos públicos persiguen.

(5) Mangas Martín, A.: Derecho comunitario europeo y Derecho español, Tecnos, Madrid, 1986, págs. 242 y 248.

(6) REMiRo BRotons, A., concluye su obra La acción exterior del Estado señalando que sería muy conveniente facilitar la participación regional en la elaboración y actuación de la política comunitaria, a través de una Comisión consultiva interregional o de un órgano similar. Tecnos, Madrid, 1984, pág. 262.

(7) Santaolalla Gadea, F., se ocupa igualmente del tema en «La aplicación del Derecho comunitario en España», Revista Documentación Administrativa, julio-septiembre 1984, págs. 201 y sigs.

(8) Mangas Martí, A.: Ob. cit. en nota 5, pág. 248.

(9) Santaolalla Gadea, F., distingue acertadamente entre ejecución administrativa y ejecución normativa. Ver trabajo citado en nota 7.

(10) MuÑoz Machado, S.: Ob. cit. en nota 3, pág. 91.

(11) La primacía del Derecho comunitario sobre el Derecho interno se ha justificado por la doctrina jurídica española desde preceptos constitucionales distintos. La doctrina internacionalista, conforme a una línea jurisprudencial mantenida por el Tribunal Supremo y recogida en la Sentencia de 30 de septiembre de 1982 (Ar. 4.917) fundamenta la primacía del Derecho de las Comunidades Europeas en base a la superioridad jerárquica de los Tratados inducida del artículo 96 de la Constitución. Si las disposiciones de un Tratado sólo pueden ser derogadas, modificadas o suspendidas en la forma prevista en los propios Tratados o de acuerdo con las normas generales del Derecho Internacional, el Tratado por esta resistencia frente a la Ley posterior adquiere una jerarquía superior. En cambio, administrativistas españoles como García DE EnTERrfa (Curso de Derecho Administrativo, vol. I, pág. 150) y MuÑoz MACHADo se apoyan en el artículo 93 del texto constitucional para justificar la primacía del Derecho comunitario en base al criterio de la competencia y no al de jerarquía postulado por los tratadistas de Derecho Internacional. Así, MuÑoz MAcHADO entiende que el Derecho comunitario desplaza al Derecho interno, de modo que éste resulta inoponible frente a aquél; pero advierte que la norma interna no queda derogada por cuanto se puede aplicar a supuestos no cubiertos por el Derecho europeo, añadiendo además que la jerarquía superior de los Tratados no explicaría convincentemente la primacía del Derecho derivado, que se fundamenta en el artículo 93 y no en el artículo 96 de la Constitución.

En cualquier caso, cabe concluir que tanto por vía del artículo 93 como del 96 se reconoce, aunque con efectos diferentes, la primacía del Derecho que emana de las Comunidades Europeas sobre el Derecho interno y, por tanto, sobre la normativa de los Entes autonómicos.

(12) A ella se refiere el artículo 113 del TCEE y afecta a aspectos relacionados con las medidas de liberalización, política de exportación, medidas de protección comercial y, entre éstas, las que deban adoptarse en el caso de dunping y subvenciones.

(13) GuY, Isaac: Derecho comunitario general, pág. 52.

(14) Giorgio BERNiNI, en "Las reglas de la competencia», obra colectiva: Treinta 
años de Derecho comunitario. Perspectivas europeas. Comisión de las Comunidades Europeas, Bruselas-Luxemburgo, 1981, pág. 396, comenta el artículo 94 del TCEE y señala que las competencias del Consejo de la Comunidad Europea en materia de ayudas, así como la facultad para dictar reglamentos que regulen el régimen general de las mismas, constituye una reserva exclusiva de la Comisión y una intencionada voluntad de los autores del Tratado de utilizar el Reglamento en vez de la Directiva, que deja mayor libertad a los Estados en lo relativo a la forma y a los medios para alcanzar el resultado exigido.

(15) Lours, Jean-Victor: Ordenamiento jurídico comunitario, Comision de las Comunidades Europeas, Bruselas, 1980, pág. 53.

(16) MARTínez LAGE, S.: "Las fuentes del Derecho comunitario», en la obra colectiva Iniciación al estudio del Derecho comunitario europeo, pág. 85.

(17) MANGas Martín, A., señala al respecto, en relación con las Comunidades Autónomas con facultades de ejecución normativa, que «cuando la competencia legislativa y reglamentaria de la Comunidad Autónoma deba tener en cuenta la legislación básica o de principios que ordene el Estado, tales principios o bases quedan sustituidos por el contenido de la disposición comunitaria». Como se puede apreciar, se sostiene un criterio distinto al que expresamos en este trabajo.

(18) MarTínez LAGE, S., trabajo citado, pág. 86.

(19) Lours, Jean-Victor, trabajo citado, pág. 56. 


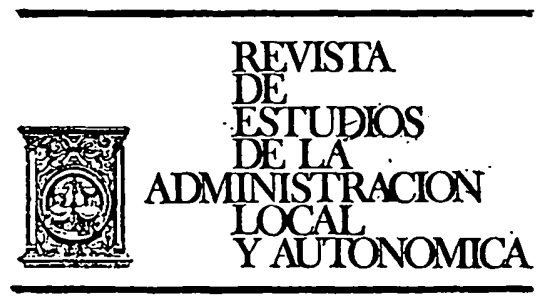

\section{CRONICAS}


REALA-1986, núm. 231. SANCHEZ DIAZ, JOSE LUIS. LA EJECUCION NORMATIVA DEL DERECH...

REALA-1986, núm. 231. SANCHEZ DIAZ, JOSE LUIS. LA EJECUCION NORMATIVA DEL DERECH... 